Session: 1547

\title{
Design of a Rain-Based Speed Controller for Automobile Windshield Wiper Motor
}

\author{
Mohammad Fotouhi, Ali Eydgahi, Tom Malaby \\ University of Maryland Eastern Shore \\ Princess Anne, MD 21853
}

\begin{abstract}
This paper describes the details of an undergraduate design project in our Design Technology course and the experience gain by the student involved. The intent of the course is to expose students to real world design projects. Students are expected to be creative and innovative in their design projects and utilize a multitude of engineering disciplines that Engineering Technology Program offers at the University of Maryland Eastern Shore. The selection of the automatic speed adjustment of windshield wiper was intended to incorporate and demonstrate the application of feedback control and photooptics. In this project, the student had to design an automated speed controller for a windshield wiper motor of a vehicle based on the amount of rainfall. The speed of rainfall in this project was determined by the amount of rain collected in semi-funnel shaped mount under-hoot with flat side against the windshield directly. An optic-electronic system was designed which uses flash converter to set the desire motor speed setting of the wiper according to the rainfall.
\end{abstract}

\section{Introduction}

Driving in the varying degrees of rainfall would sometimes cause automobile operators to loose sight of the centerlines and shoulder of the road. Specially, driving in the evening through some inconsistent rainy weather. The driver constantly has to remove one hand from the steering wheel to adjust the sweep speed of the windshield wiper. At the times when the rainfalls are the hardest, the vehicles that usually approach from the other direction would have a blinding effect on the operator. This problem is even more severe with headlight glare caused by water on the windshield. This is not the time for driver to be removing one hand from the steering wheel to adjust the speed of windshield wipers. Then, within seconds of this potentially deadly situation, the rain changes to a light mist and wipers are producing a rather loud, annoying, and screeching sound. Again, drivers have to remove one hand from the steering wheel trying to find that precise wiper speed that will relinquish the annoying screeching sound.

The speed of windshield wipers (WSW) is usually set by a multi-position switch in many vehicles. During the heavy rainfall, the higher speed setting of WSW is required. The 
high speed setting is in most instances bothersome to driver's eyes and will cause the wipers to produce squeaking noise if the rainfall slows down. This will require the driver constantly change the speed setting of the wipers or bear the constant nuisance squeaking noise which can be distracting and dangerous in major metropolitan cities.

An automatic speed controller for windshield wiper could monitor the amount of rainwater striking the windshield and then adjust the wipers motor speed proportionately to make driving in storms not only easier but also safer. This would free the drivers from constantly worrying about the right wiper speed setting and allows them to concentrate more on driving.

\section{Design of the System}

\section{i- Mechanical Part}

The body of this device is a simple funnel shaped in such a fashion as to allow it to collect rainwater from the upper edge of a car windshield (an elongated oval shape). The water that the funnel collects is directed down a rubber tube that is connected to the top end of a rigid clear plastic tube mounted upright. The rigid tube also has a drain at the bottom that allows water to escape the system. As the plastic tube fills with water it moves a reflective floatation device from bottom to top on the inside of the tube.

\section{ii- Electronics Part}

The electronics circuit in this project is photo-optic infrared emitters and receivers ${ }^{1-3}$. Parallel to the clear plastic (flow) tube there is a column of infrared light-emitting diodes (LED) which are placed such that ninety degrees around the side of the flow tube from the LED there is another similar column of phototransistors detectors which are facing into the center of the tube. As the drain at the bottom of the flow tube starts to back up with water due to increasing of the rainfall the buoyant reflective object in the tube moves up and reflects the infrared LED signal into the adjacent phototransistors. While the phototransistors detectors response to the incoming infrared light and turn on, they consecutively energize the coils in several individual relay switches. Each relay switch closes a circuit that draws from a voltage divider network of resistors. This consequently produces the voltages from the voltage divider networks and is received in steps to drive the direct current (DC) motor that operates the windshield wipers. The current amplification was necessary between the voltage divider network and the DC motor. Therefore, some power transistors were employed. Figure 1 shows the designed electronic Circuit.

\section{Operation of the System}

After a switch initially turns on the array of infrared LED and the voltage divider network, a small amount of water backing up in the flow tube causes the wipers to come on at their slowest speed. At this step a simple timer circuit could be employed to cause a 
delayed wiper sweep. As the water gradually backs up inside the tube, the wiper motor speeds up proportionately. Then, as the system overflows, the reflective device would be set at the fastest setting.

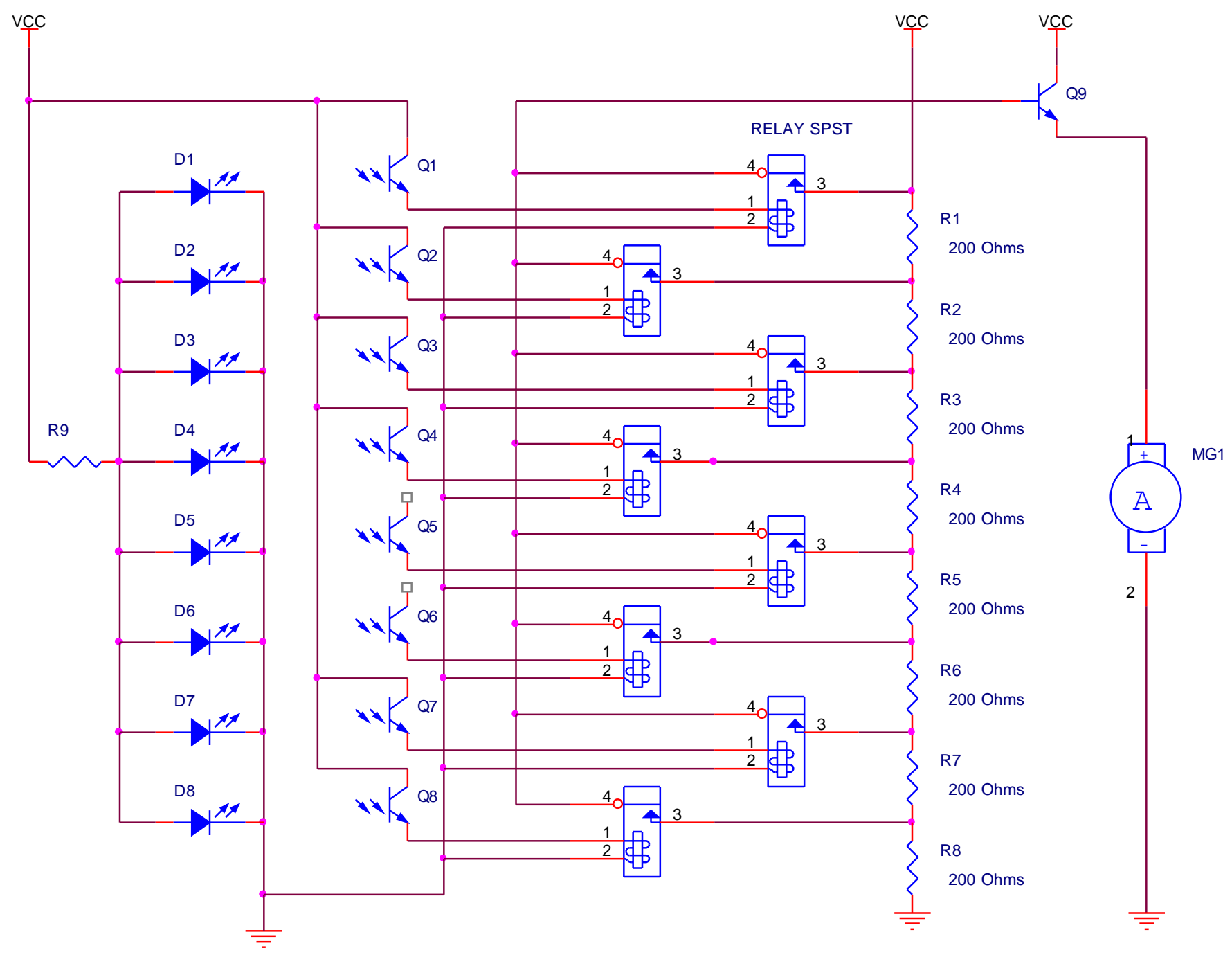

Figure 1: The Designed Electronic Circuit

\section{Conclusion}

This project was implemented in laboratory setting to demonstrate its objectives. We used a 12 volt DC motor instead of an actual windshield wiper itself. The project performed perfectly and provided the intended result of the original concept. It was observed that if more components are employed in the system, the better the system 
serves its purpose. To have more in between speeds is certainly an advantage and to have them selected automatically would definitely allow the driver to keep his eyes on the road and his hands on the wheel.

\section{Bibliographies}

1. Wildi, T., Electrical Machines, Drives and Power System, Prentice Hall, N. J. 2000.

2. Carr, J.J., Elements of Electronic Instrumentation and Measurements, Prentice Hall, N.J., 1996.

3. Maloney, T.J., Modern Industrial Electronics, Prentice Hall, N.J., 1996.

\section{MOHAMMAD FOTOUHI}

Dr. Fotouhi is a Professor of electrical engineering technology at University of Maryland Eastern Shore. He received his Ph.D. in power System Engineering from University of Missouri-Rolla and M.S. from Oklahoma State University. He was chairman of Student and Industry Relation and Host Committee member of IEEE Conference on Power Systems Computer Application and IEEE Power Society Winter Meeting in 1991 and 1996, respectively.

\section{ALI EYDGAHI}

Dr. Eydgahi is a Professor of electrical engineering at University of Maryland Eastern Shore. He received his Ph.D. and M.S. in Electrical and Computer Engineering from Wayne State University. He is the ASEE Campus Representative at UMES and has served as a session chair and a member of scientific and international committees for many international conferences. He has published more than eighty papers in refereed international and national journals and conference proceedings.

\section{TOM MALABY}

Mr. Malaby received his B.S. in Electrical Engineering Technology from University of Maryland Eastern Shore in 2001. He is currently an engineer at NASA facility at Wallops Island, VA. 